morning stiffness (minutes) fatigue, sleep disturbances and other vegetative and functional symptoms. Severity of depression was also evaluated with Hamilton Depression Rating Scale, 17-item version (HDRS).

Results 12 from 17 patients (70\%) showed a clinical improvement at the end of the study as a consequence of the reduced intensity of pain $(8,1$ before, 4,6 after therapy, $\mathrm{p}<0,001)$, morning stiffness (57,6 min.vs 36,8 min., $\mathrm{p}<0,005)$, fatigue $(8,3$ vs $5,3, \mathrm{p}<0,001)$, sleep disturbances $(8,2$ vs $2,5, \mathrm{p}<$ $0,0005)$, headache $(7,1$ vs $4,2, p<0,005)$, gastrointestinal symptoms $(6,1$ vs $2,4, \mathrm{p}<0,005)$ or paresthesia $(8,5$ vs $4,8, \mathrm{p}$ $<0,005)$. The reduced severity of depressive symptoms was also observed $(17,7$ vs $6,8, \mathrm{p}<0,001)$. Six patients complained of sleepiness and hypotension during the first days of therapy, in three cases dosis of mirtazapine was reduced to $15 \mathrm{mg}$ and treatment continued, three patients (female) were excluded from the study.

Conclusion Our data suggest that mirtazapine could be an effective and promissing method in the treatment of fibromyalgia patients. During the treatment of FS patients strict cooperation beetween rheumatologists and psychiatrist is needed.

\section{SAT0142 EFFICACY ANALYSIS OF LOW-ENERGY LASER THERAPY IN TREATMENT OF FIBROMYALGIA}

M Terek, G Radunovic. Clinical VI, Institute of Rheumatology, Belgrade, Yugoslavia

10.1136/annrheumdis-2001.601

\section{Background}

Objectives The aim of the study was to investigate the efficacy of low-energy laser therapy versus placebo in treatment of patients with fibromyalgia.

Methods We followed 36 female patients (age from 31 to 51 years, mean age 41.94 years) with fibromyalgia according to latest American College of Rheumatology (ACR) criteria for diagnosis. The first group of 18 patients was treated with low-energy laser 10 times every other day by scanning each of tender points with single therapy doze of $40 \mathrm{~J}$. Identical procedure was preformed in the second group of 18 patients, but low-energy laser diode was switched-off. All patients from both groups took similar drugs - NSAIDs and benzodiazepines, also had similar lowimpact and stretching exercises. We measured the count of tender points, pain intensity with four-scale questionnaire; also sleep disturbance and malaise with similar four-scale questionnaire, before and after therapy procedure. Results were statistically analysed with Wilcoxon matched pairs test within groups of patients and with Mann-Whitney U test between groups.

Results In both groups we found statistically significant lowering of count of tender points $(\mathrm{p}<0.001)$, pain intensity $(\mathrm{p}<$ $0.001)$, sleep disturbance $(\mathrm{p}<0.001)$ and malaise $(\mathrm{p}<0.001$ in the first group and $p<0.05$ in the second) after therapy procedure. Between groups we found that lowering of all followed disease parameters was more clearly in the first group and all differences were statistically significant $(p<0.0001$ for all parameters).

Conclusion Treatment of patients with fibromyalgia with lowenergy laser therapy improves symptoms of disease more than placebo. This statement suggests that low-energy laser therapy have prominent place in up to date treatment of patients with fibromyalgia, especially because of patient's tolerance, no contraindications and simple applicability.
SAT0143 PSYCHOSOMATIC ASPECTS OF FIBROMYALGIA VERSUS RHEUMATOID ARTHRITIS

${ }^{1}$ CA Silva, ${ }^{2} \mathrm{MJ}$ Quartilho, ${ }^{1} \mathrm{JA}$ Da Silva, ${ }^{1} \mathrm{~A}$ Malcata, ${ }^{1} \mathrm{~A}$ Porto. ${ }^{1}$ Rheumatology Department; ${ }^{2}$ Psychiatry Department, University Hospital of Coimbra, Coimbra, Portugal

10.1136/annrheumdis-2001.602

Background The psico-social dimensions of fibromialgia (FM) remain controversial, not only regarding its characterisation but also its possible causal or consequential relationship with the chronic pain status. The usual discrepancy between the selfreport instruments of functional impairment and the observed disability favours a process of somatization. The contribution of pain and emotions to general health status are open to debate.

Objectives We attempted to investigate emotional disturbances in patients with fibromialgia and rheumatoid arthritis (RA) and their relationship with self-reported general health.

Methods $58 \mathrm{FM}$ patients and 43 RA patients, fulfilling the ACR criteria, were included on a consecutive basis from our Rheumatology outpatient clinic. Social and demographic data were collected and found to be comparable among the groups, as well as disease duration. The Short-Form Health Survey (SF-36) and the Brief Symptom Inventory (BSI) were applied twice, with 6 months interval. Both instruments were evaluated regarding each of their different dimensions and summary score. Statistical analysis employed Student's t test.

Results FM patients scored significantly higher in every single BSI dimension (somatization; obsession/compulsion; interpersonal relationship; depression; anxiety; hostility; fobic anxiety, paranoid ideation and psicoticism. FM patients also showed significantly lower levels of general health, as evaluated by SF36 , both in mental and physical components. These differences remained stable in re-evaluation.

Conclusion FM patients have a higher score for associated psychopathologic symptoms. This parallels their higher dissatisfaction with general health, not only in its mental aspects, but also on physical function and performance. These results demonstrate a strong coexistence of pain and psichopatological traits in FM patients, which may have a strong influence on reported functional status. The possibility that such psychological disturbances are a consequence of the disease, and especially chronic pain, is questioned by the much lower prevalence of such disorders in RA patients of similar disease duration.

\section{SAT0144 THE 24-HR URINARY EXCRETION OF 6- SULPHATOXYMELATONIN AND 5- HYDROXYINDOLEACETIC ACID IN WOMEN WITH PRIMARY FIBROMYALGIA AND CHRONIC LOW BACK PAIN}

${ }^{1} \mathrm{P}$ Hrycaj, ${ }^{2} \mathrm{~J}$ Kelemen, ${ }^{2} \mathrm{~T}$ Stratz, ${ }^{2} \mathrm{~W}$ Müller. 'Department of Rheumatology and Clinical Immunology, Karol Marcinkowski University School of Medical Sciences, Poznan, Poland; ${ }^{2}$ Department Für Die Grundlagenforschung in Der Rheumatologie, Hochrhein-Institut Für Rehabilitationsforschung E. V., Bad Säckingen, Germany

\subsection{6/annrheumdis-2001.603}

Background Fibromyalgia syndrome (FS) is characterised by chronic "widespread" musculoskeletal pain, presence of multiple tender points, fatigue, depression/anxiety, and sleep disturbance. Recently, evidence has accumulated to link the FS pathogenesis to serotonin (5-hydroxytryptamine, 5-HT) deficiency. Since melatonin, a pineal hormone responsible for the regulation of sleep 